\title{
Clostridium difficile Infection: Update on Diagnosis, Epidemiology, and Treatment Strategies
}

\author{
Kathleen B. To and Lena M. Napolitano
}

\begin{abstract}
Background: Clostridium difficile infection (CDI) has increased in incidence and severity over the past quarter century, and is now considered a major cause of healthcare-associated infections.

Methods: Review of the pertinent English-language medical literature.

Results: There has been a substantial change in the management of CDI. The emergence of the NAP1/BI/O27 strain in the early to mid-2000s has been associated with more severe forms of CDI. The pathophysiology, epidemiology, clinical manifestations and diagnosis, as well as new strategies for medical and surgical management are discussed in this review.

Conclusions: Clostridium difficile infection can range from benign diarrhea to severe disease associated with substantial morbidity and mortality. Treatment modalities vary based on disease severity and timing of onset. The mainstay of medical treatment remains metronidazole and oral/rectal vancomycin. New management strategies are evolving, including adjunctive treatments such as monoclonal antibodies, vaccination, and fecal transplant. In patients with severe disease or clinical deterioration, early surgical consultation for total colectomy or loop ileostomy may be life-saving. Infection control measures are vital to mitigating the spread of CDI.
\end{abstract}

D URING THE PAST 20 YEARS, THE INCIDENCE and severity of Clostridium difficile infections have increased dramatically, especially with the emergence of the NAP1/BI/ O27 strain in the early-to-mid-2000s. Clostridium difficile is now considered one of the most important causes of healthcare-associated infections, and community-acquired $C$. difficile disease also has emerged as an important entity. Both medical and surgical management of $C$. difficile colitis have changed over the past decade. This review provides an update regarding pathophysiology, epidemiology, clinical manifestations and diagnosis, current medical and surgical management, and opportunities for advancement in treatment modalities for $C$. difficile infection (CDI).

\section{Pathophysiology}

Clostridium was first cultured by Hall and O'Toole in 1935 from the feces of healthy newborns [1]. It was named " $\mathrm{Ba}$ cillus difficilis" due to the difficulty in culturing this slowgrowing, gram-positive bacillus from an anaerobic medium. While of academic interest, the $C$. difficile bacterium was not believed to be important clinically significant until the late 1970s, when its pathogenic role in antibiotic-associated diarrhea and pseudomembranous colitis was described [2]. We now know that $C$. difficile is a rod-shaped sporulating, anaerobic gram-positive bacillus whose potent toxins can cause symptoms ranging from mild diarrhea to life-threatening pseudomembranous colitis and toxic megacolon. Its virulence is related to the production of endospores and endotoxins $\mathrm{A}$ and $\mathrm{B}$.

The life cycle of the $C$. difficile bacterium is shown in Figure 1 [3]. Transmission occurs via ingestion of spores and vegetative cells. Most of the vegetative cells are killed by gastric acid. The spores, on the other hand, can survive the acidic gastric environment and will germinate in the small bowel upon exposure to bile acids. These newly flagellate bacteria then migrate to the colon where they can multiply, especially in the setting of antibiotic-induced changes to the composition of colonic flora. The bacteria adhere to the gut mucosa and produce toxins A and B, which leads to a massive inflammatory response cascade, epithelial cell junction opening and apoptosis, and degradation

Department of Surgery, University of Michigan, Ann Arbor, Michigan. 


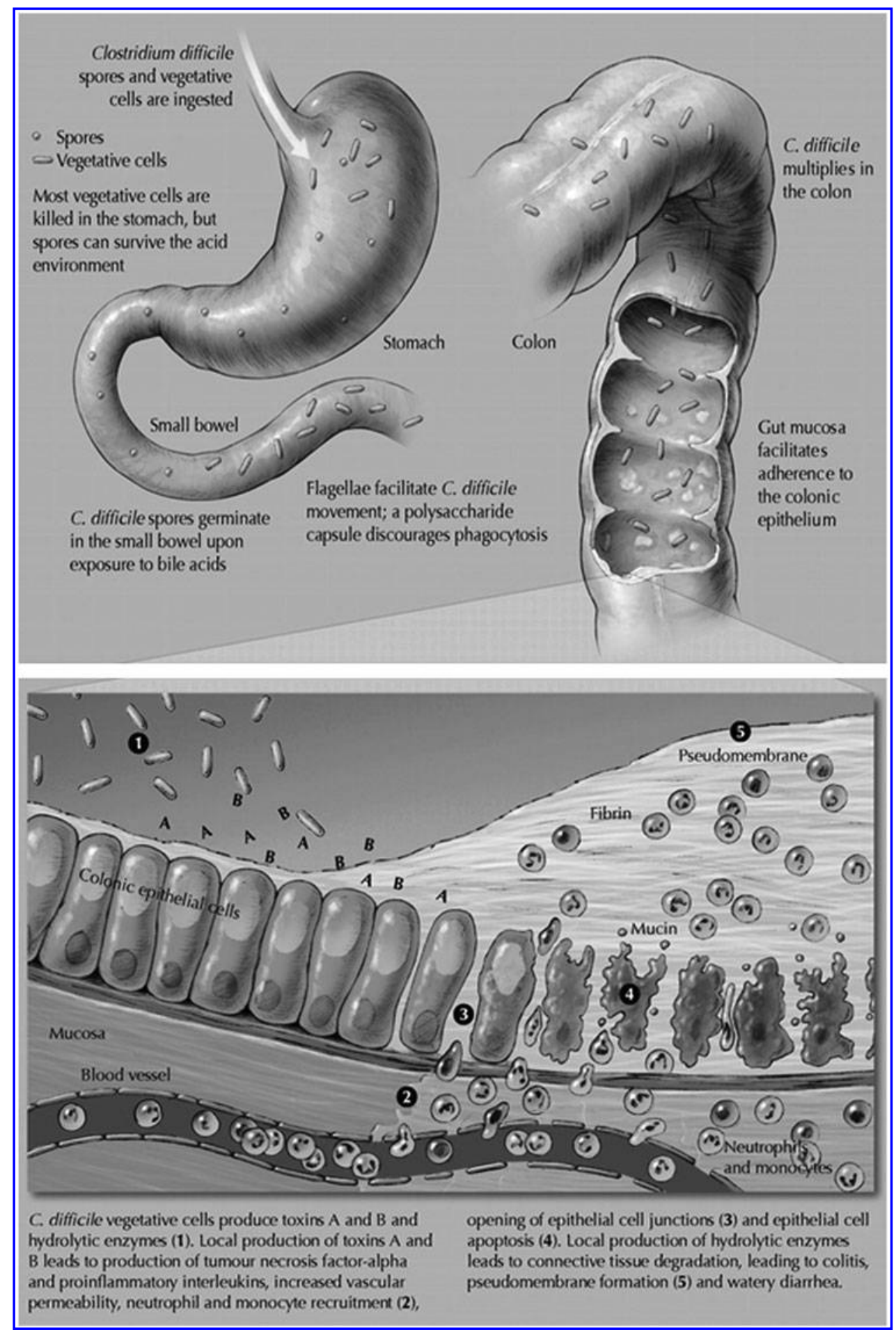

FIG. 1. Lifecycle of the Clostridium difficile bacterium. From Poutanen and Simor [3].

of connective tissue by hydrolytic enzymes. The end result is the development of pseudomembranous colitis and watery diarrhea.

Clostridium difficile can be part of the normal colon flora colonizing the colon of an asymptomatic carrier. However, when there is an alteration to the composition of normal colonic flora, it can lead to organism overgrowth and toxin elaboration. Kyne et al. showed that as many as $31 \%$ of patients who received antibiotics were colonized with $C$. diffi- cile, and $56 \%$ of these patients subsequently developed symptomatic $C$. difficile disease [4].

The $C$. difficile bacterium produces two distinct toxins. Toxin $\mathrm{A}$ is an enterotoxin that causes local tissue damage and fluid secretion along with the inflammatory response. This is the less potent of the two toxins produced. Toxin B activates the release of cytotoxins from monocytes, leading to the destruction of the cytoskeleton. Toxin B is approximately 1,000 times more potent than toxin A. In some strains of 
Table 1. Classification of Clostridium difficile Infection (CDI) Based on Exposure Setting and Timing

\begin{tabular}{ll}
$\begin{array}{l}\text { Disease } \\
\text { classification }\end{array}$ & \multicolumn{1}{c}{ Definition } \\
\hline $\begin{array}{l}\text { HCF onset, HCF- } \\
\text { associated CDI }\end{array}$ & Symptom onset $\geq 48 \mathrm{~h}$ after admission and before discharge from a HCF \\
$\begin{array}{c}\text { Community onset, } \\
\text { HCF-associated CDI }\end{array}$ & $\begin{array}{c}\text { Symptom onset in the community or within } 48 \mathrm{~h} \text { of admission to a HCF, } \\
\text { provided symptom onset was } \leq 4 \text { weeks after the last discharge from a HCF. } \\
\text { Community- }\end{array}$ \\
$\begin{array}{c}\text { Symptom onset in the community or within } 48 \mathrm{~h} \text { of admission to an HCF, } \\
\text { provided symptom onset was }>12 \text { weeks after the last discharge from a HCF. } \\
\text { Indeterminate CDI } \\
\text { Unknown CDI }\end{array}$ & $\begin{array}{c}\text { Symptom onset does not fit any of the above criteria for an exposure setting } \\
\text { Exposure setting cannot be determined because of lack of available data }\end{array}$
\end{tabular}

From: McDonald et al. [4].

$\mathrm{HCF}=$ healthcare facility .

C. difficile, the $t c d-A$ and $t c d-B$ genes also produce a binary toxin, the clinical implications of which are as yet uncertain.

\section{Classification and Definitions}

Clostridium difficile infection is associated commonly with diarrhea, defined as $\geq 3$ stools in less than $24 \mathrm{~h}$. However, the lack of diarrhea does not preclude a CDI, as approximately $1 \%$ of patients may present with ileus and colonic distention rather than diarrhea. Symptoms may vary from mild diarrhea treated on an outpatient basis to fulminant severe colitis requiring multimodal therapy, intensive care unit (ICU) support, and possible diverting ileostomy or total abdominal colectomy. Extent and duration of CDI treatment is based on clinical severity.

Most patients with CDI will have a recent history of antimicrobial or antineoplastic treatment. However, there are increasing reports of cases from the community that have not been preceded by antimicrobial use. For epidemiologic surveillance, distinction is made between community-onset, community-associated, healthcare facility-onset and healthcare facility-associated CDI. Cases where symptom onset or exposure setting do not fit criteria or cannot be determined are classified as "indeterminate" or "unknown," respectively. Detailed criteria for classification are listed in Table 1 and Figure 2 [5].

\section{Epidemiology}

Prior to the 2000s, the rate of CDI did not vary much from year to year. However, in the past decade and a half, the total number of cases reported has increased dramatically by approximately $25 \%$ per year. During the mid- and late-1990s, the reported incidence of CDI in acute care hospitals in the United
States was stable at 30 to 40 cases per 100,000 population, with an increase to 50/100,000 cases in 2001 and 84/100,000 cases in 2005 - nearly three times the baseline rate of 31/100,000 in 1996 [6]. The incidence and severity of CDI has been on the increase over the last 10 to 20 years, and it is described increasingly outside healthcare settings and in populations previously believed to be at low risk [7].

There also has been a substantial increase in the morbidity, mortality and economic burden associated with CDI in the last several years [8,9]. Increasing rates of severe and fatal infections are of great concern. Clostridium difficile infection was reported as the primary cause of death in England for 499 patients in 1999; this number increased to 2,998 in 2005 and 3,933 in 2006 [10]. The 2003 outbreak in Quebec, Canada was notable, with a reported four-fold increase in the incidence of CDI from 22.2 and 25.2 per 100,000 population (in 1991 and 2002 , respectively) to 92.2 per 100,000 in 2003 [11]. This outbreak was associated with major mortality, with $C$. difficile as the attributable cause of death in $6.9 \%$ of cases and as a contributing factor in an additional $7.5 \%$ of cases [12].

A recent multicenter study documented that $\mathrm{CDI}$ is a common nosocomial infection in mechanically-ventilated ICU patients $(n=386 ; 6.6 \%$ of a total cohort of 5,852 patients), and that septic shock occurred in $34.7 \%$ of patients. For $C$. difficile patients, the mortality rate was high $(25.1 \%)$ and prolonged hospital (23 d vs. $15 \mathrm{~d} ; \mathrm{p}<0.001)$ and ICU (12 d vs. $8 \mathrm{~d}$; p < 0.001) length of stay (LOS) were noted, with increased need for skilled nursing care or rehabilitation following hospital discharge [13].

A major contributor to this increase was the emergence of a new strain of $C$. difficile, the toxigenic strain III NAP1/BI/ O27. Between 2002 and 2006, this particular strain gained

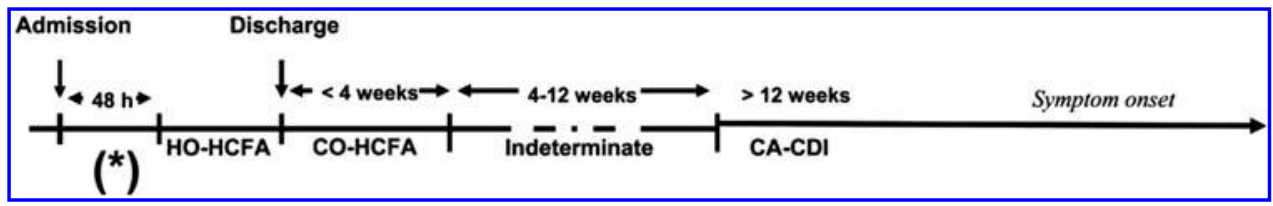

FIG. 2. Timeline for surveillance definitions of Clostridium difficile-associated infection (CDI) exposures.

A case patient who had symptom onset during the window of hospitalization marked by an asterisk (*) would be classified as having community-onset, healthcare facility-associated disease (CO-HCFA) if the patient had been discharged from a healthcare facility within the previous four weeks; would be classified as having indeterminate disease if the patient had been discharged from a healthcare facility within the previous four to 12 weeks; or would be classified as having community-associated CDI (CA-CDI) if the patient had not been discharged from a healthcare facility in the previous 12 weeks. $\mathrm{HO}-\mathrm{HCFA}=$ healthcare facility-onset, healthcare facility-associated CDI. From Conen et al. [15]. 
public notoriety as the cause of a deadly new epidemic; as of 2010 this strain has spread to 40 U.S. states, seven Canadian provinces, as well as England, continental Europe, and Asia $[14,15]$. The NAP1 strain is associated with the use of fluoroquinolones, and contains an 18-pair deletion as well as a novel single-base deletion in the $t c d-C$ gene, which results in overproduction of toxins $\mathrm{A}$ and $\mathrm{B}$, as well as the emergence of a binary toxin whose clinical significance has not been elucidated yet [16,17]. Clinically, patients manifest more severe cases of CDI, with more presentations of toxic megacolon than diarrhea, profound leukemoid reactions, severe hypoalbuminemia, septic shock, and increased mortality. A recent analysis identified the key genetic changes linked to the rapid transcontinental dissemination of this epidemic $C$. difficile and its spread throughout the global healthcare system [18].

Epidemiologic data confirm that CDI also is increasing in surgical patients in the United States, with a 34\% increase over a 5-y period (1999-2003). In particular, CDI was most prevalent after emergency surgery and among patients having intestinal tract resections. Multivariable analysis demonstrated that $C$. difficile was an independent predictor of LOS, which increased by $16.0 \mathrm{~d}$, (95\% confidence interval [CI] 15.6-16.4; $\mathrm{p}<0.0001)$ in the presence of infection. Total charges increased by $\$ 77,483$ (95\% CI $\$ 75,174-\$ 79,793$; $\mathrm{p}<0.0001$ ), and there was a 3.4-fold increase in the mortality rate $(95 \%$ CI 3.02-3.77; $\mathrm{p}<0.0001)$, compared with patients who did not acquire $C$. difficile [19].

The 2010 clinical practice guidelines for $C$. difficile infection in adults-published by the Society for Healthcare Epidemiology of America (SHEA) and the Infectious Disease Society of America (IDSA) - make the following evidence-based recommendations with regard to epidemiologic surveillance for CDI: To increase comparability between clinical settings, use available standardized case definitions for surveillance of 1) healthcare facility (HCF)-onset, $\mathrm{HCF}$ associated CDI, 2) community-onset, HCF-associated CDI, and 3) community-associated CDI (Fig. 2; strength of evidence and recommendation $\mathrm{B}-\mathrm{III})$; at a minimum, conduct surveillance for $\mathrm{HCF}$-onset, $\mathrm{HCF}$-associated $\mathrm{CDI}$ in all inpatient healthcare facilities, to detect outbreaks and monitor patient safety (B-III); express the rate of healthcare-associated CDI as the number of cases per 10,000 patient-days (B-III); and if CDI rates are high, compared with those at other facilities, or if an outbreak is noted, stratify rates by patient location in order to target control measures (B-III).

\section{Risk Factors}

Classically, any exposure to antibiotics (particularly clindamycin, ampicillin or amoxicillin, cephalosporins and fluoroquinolones) was a major risk factor for the development of CDI. However, there has been emergence of communityacquired CDI where antimicrobial exposure does not precede clinical infection. Age older than 65 y alone confers a 16.3-fold risk for development of CDI. Increased length of hospital stay, manipulation of the gastrointestinal tract (e.g., surgery), immunosuppressed state (e.g., chemotherapy, HIV + patients, and medical comorbidities leading to immunosuppression) also make the patient more susceptible to developing CDI. There also has been much debate regarding the role of acid-suppressive medications such as histamine- 2 receptor antagonists and proton pump inhibitors in the development of CDI [20-22].

\section{Clinical Manifestations}

The spectrum of CDI ranges from the asymptomatic carrier (found in 7-26\% of adults in acute care facilities) to mild/ moderate diarrhea to fulminant colitis and pseudomembranous colitis resulting in multiple organ dysfunction syndrome and death. Infection can manifest as multiple loose stools with passage of mucus or occult in milder cases of CDI; frank melena or hematochezia are rare. With more severe forms of CDI, patients may develop unexplained profound leukocytosis, colonic ileus, or toxic megacolon seen on abdominal imaging with minimal to no diarrhea. The NAP1/ BI/O27 strain of $C$. difficile has been associated with these more severe clinical manifestations of CDI in major outbreaks around the world [17].

\section{Diagnosis}

\section{Laboratory studies}

The diagnostic tests of choice are either a stool sample positive for $C$. difficile or its toxins, or colonoscopic/histopathologic findings of pseudomembranous colitis. According to the 2010 SHEA/IDSA clinical practice guidelines, the gold standard for diagnosis of CDI is with toxigenic stool culture; however, this is not practical for routine diagnosis and has been recommended for epidemiologic studies only. Stool samples should only be collected from symptomatic patients with diarrhea unless colonic ileus is suspected. The recommended route for testing is the use of a two-step algorithm,

Table 2. Diagnostic Testing for Clostridium Difficile

\begin{tabular}{|c|c|c|c|c|c|}
\hline Test & Sensitivity & Specificity & Availability & Expense $^{\mathrm{a}}$ & Utilization \\
\hline $\begin{array}{l}\text { C. difficile } \\
\text { culture }\end{array}$ & Low & Moderate & Limited & $\$ 5-10$ & $\begin{array}{l}\text { No diagnostic use; only toxigenic organisms } \\
\text { cause disease }\end{array}$ \\
\hline $\begin{array}{l}\text { Toxigenic } \\
\text { culture }\end{array}$ & High & High & Limited & $\$ 10-30$ & $\begin{array}{l}\text { Reference method epidemiologic tool } \\
\text { Limited diagnostic use }\end{array}$ \\
\hline CCNA & High & High & Limited & $\$ 15-25$ & Reference method, limited diagnostic use \\
\hline GDH & High & Low & Wide & $\$ 5-15$ & Diagnostically as a screening test; must be confirmed \\
\hline Toxin EIA tests & Low & High & Wide & $\$ 5-15$ & Must detect toxins $\mathrm{A}+\mathrm{B}$; inferior sensitivity \\
\hline NAATs & High & High & Wide & $\$ 20-50$ & Use only in acute disease; false-positives of concern \\
\hline
\end{tabular}

From Surawicz et al. [25]. (Reprinted by permission from Macmillan Publishers Ltd.).

${ }^{a}$ Cost of goods; does not reflect laboratory changes.

$\mathrm{CCNA}=C$. difficile cytotoxin neutralization assay; GDH = glutamate dehydrogenase EIA = enzyme immunoassay; NAATs = nucleic acid amplification tests. 
which employs a glutamine dehydrogenase (GDH) assay for the $C$. difficile antigen, followed by enzyme immunoassay (EIA) toxin testing. If the antigen is positive and toxin is negative, some laboratories will send the specimen for polymerase chain reaction (PCR) testing as a final confirmatory step. Nucleic acid amplification tests (NAATs) such as PCR are superior to EIA in terms of sensitivity and specificity (Table 2) but are much more costly, and false positives may result in inappropriate treatment. It is important to note that when results are negative, repeat testing is of limited value [23-25]. Furthermore, testing for cure is not recommended.

\section{Adjunctive studies}

In cases where index of suspicion is high in the absence of a diarrheal specimen for laboratory testing, endoscopic evaluation of the colon may be helpful. The classic endoscopic description is of normal-to-patchy, nonspecific colitis with inflamed mucosa studded with adherent raised white and yellow plaques (Fig. 3, Panel A), but nodular $C$. difficile colitis has also been reported (Fig. 3, Panel B) [26,27]. It is important to note that the false-negative rate for endoscopy may be as high as $10-25 \%$. Also, in patients suspected of having fulminant colitis and toxic megacolon, there is an increased risk for perforation during endoscopic evaluation.

Radiologic evaluation may be useful adjuncts in evaluating the critically ill patient for possible CDI. Plain abdominal

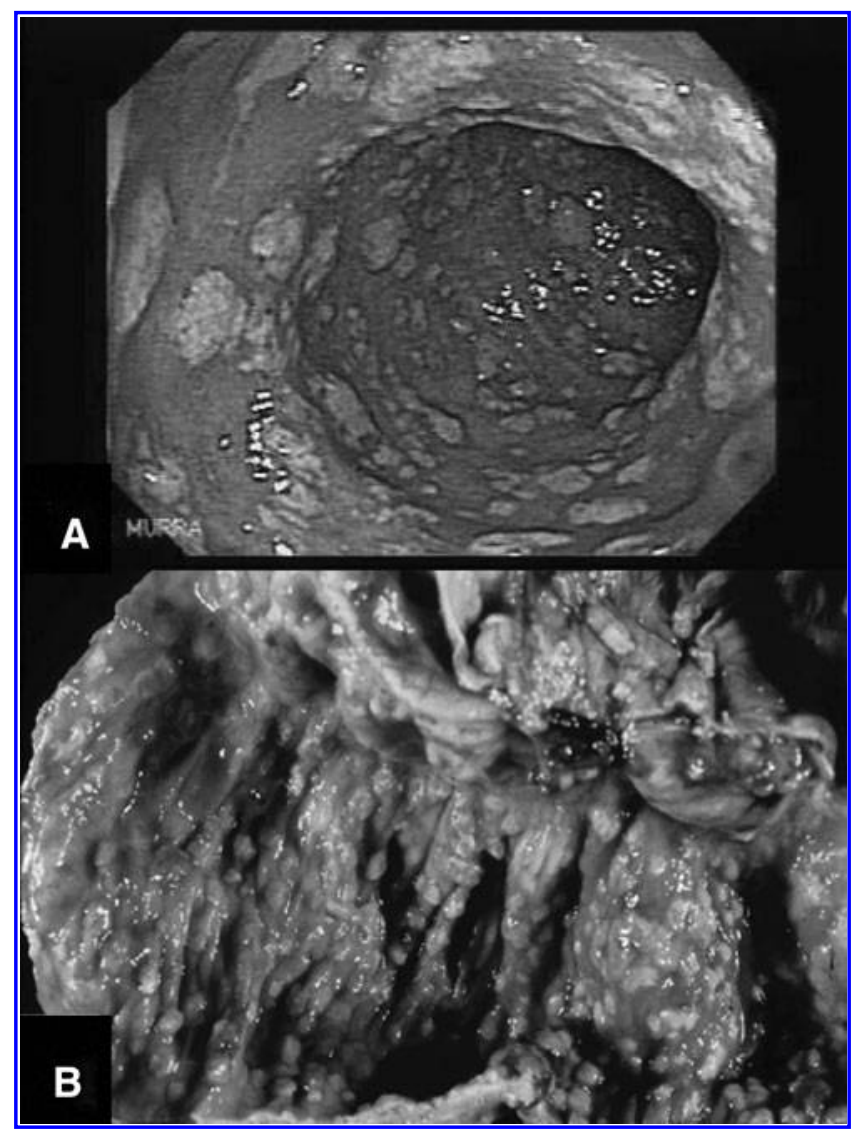

FIG. 3. Findings of Clostridium difficile colitis. (Courtesy of Dr. Julio Murra-Saca, Hospital Centro de Emergencias [26]; Reprinted with permission from Medscape [27].)
X-rays may show dilated colon consistent with toxic megacolon. Computed tomography (CT) may show "thumbprinting" of the mucosa indicative of colonic mucosal edema, wall thickening, abnormal bowel wall attenuation (target sign), nodular fold thickening, the "accordion" sign (alternating edematous haustral folds separated by transverse mucosal ridges filled with enteral contrast material), fat stranding, or in severe cases, ascites or perforation. Overall computed tomography (CT) sensitivity is $52-85 \%$, with specificity of $48-93 \%$ $[28,29]$. Some institutions advocate more rigid adherence to CT scan diagnostic criteria for $C$. difficile colitis of colon wall thickening of greater than $4 \mathrm{~mm}$ combined with any one or more findings of pericolonic stranding, colon wall nodularity, the "accordion" sign, or otherwise unexplained ascites, with a reported sensitivity of $70 \%$ and specificity of $93 \%$ [30].

\section{Medical Management}

\section{Current standard of care}

The first step in treatment of $C$. difficile disease is cessation of all antibiotics if possible. Prompt appropriate fluid resuscitation, electrolyte normalization, discontinuation of all antiperistaltic agents (including narcotics) that inhibit the elimination of intestinal luminal toxin, and correction of any other concomitant organ dysfunction remain the initial mainstay of therapy in $C$. difficile disease.

According to the 2010 SHEA/IDSA guidelines, metronidazole is the initial drug of choice for the treatment of mildto-moderate CDI, with oral vancomycin reserved for more severe cases, and the addition of vancomycin retention enemas in severe or complicated cases of CDIs (Table 3A) [15,31]. Numerous studies have examined the efficacy of metronidazole versus oral vancomycin for the treatment of CDI. Vancomycin is one of only two U.S. Food and Drug Administration (FDA)-approved drug for the treatment of CDIs, and overall has a higher rate of cure, especially in more severe cases of CDI. Oral vancomycin also has a lower treatment failure rate, as there is evidence of some $C$. difficile strains showing metronidazole resistance in vitro. However, for milder cases of CDI, the difference between the two drugs is marginal ( $96 \%$ for vancomycin and $90 \%$ for metronidazole); thus, due to concerns regarding cost and potential emergence of vancomycin-resistant Enterococcus, metronidazole is still the preferred initial agent for these milder infections [17,32-34].

In patients with a first recurrence of CDI, the recommended treatment algorithm is the same as for the index episode; however, for patients with multiple recurrences, oral \pm rectal vancomycin in a tapered or pulsed regimen is recommended due to concern for neurotoxicity from cumulative metronidazole dosing (Table 3B; Fig. 4; Fig. 5) [14,28,32].

\section{Alternative medications and adjunctive therapies}

New treatment strategies for CDI are needed, and important data have emerged recently for new anti- $C$. difficile antibiotics including fidaxomicin, rifampin, rifaximin, rifalazil, nitazoxanide, tigecycline, and ramoplanin [36,37].

\section{Fidaxomicin}

Fidaxomicin (OPT-80) is a macrocyclic antibiotic with a narrow antimicrobial spectrum. Most of its activity is against $C$. difficile, most strains of staphylococci, and 
TABle 3A. Guidelines for Treatment OF INITIAL CLOSTRIDIUM DIFFICILE INFECTION

\begin{tabular}{|c|c|}
\hline Initial episode & Recommended treatment \\
\hline Mild-moderate CDI & $\begin{array}{l}\text { Metronidazole } \\
500 \mathrm{mg} \mathrm{PO} / \mathrm{IV}^{\mathrm{TID}^{1}}\end{array}$ \\
\hline $\begin{array}{l}-\mathrm{WBC}<15,000 \text { cells } / \mathrm{mm}^{3} \\
\text { and } \\
\text {-creatinine }<1.5 \times \text { baseline }\end{array}$ & $10-14 \mathrm{~d}$ \\
\hline Severe CDI & $\begin{array}{l}\text { Vancomycin } 125 \mathrm{mg} \\
\text { PO QID (FDA approved) }\end{array}$ \\
\hline $\begin{array}{l}-\mathrm{WBC}>15,000 \text { cells } / \mathrm{mm}^{3} \\
\text { or } \\
\text {-creatinine }>1.5 \times \text { baseline }\end{array}$ & $10-14 \mathrm{~d}$ \\
\hline Severe, complicated CDI & $\begin{array}{l}\text { Vancomycin } 500 \mathrm{mg} \\
\text { PO QID }\end{array}$ \\
\hline $\begin{array}{l}\text {-same as for severe CDI } \\
\text { and }\end{array}$ & $\begin{array}{l}\text { 土 IV metronidazole } \\
500 \mathrm{mg} \text { IV g8h }\end{array}$ \\
\hline $\begin{array}{l}\text {-hypotension/shock, } \\
\text { ileus, toxic megacolon, } \\
\text { perforation, need } \\
\text { for colectomy, } \\
\text { or ICU admission }\end{array}$ & $\begin{array}{l}\text { Vancomycin } 500 \mathrm{mg} \\
\text { in } 100 \mathrm{~mL} \text { NS q6h as } \\
\text { retention enema (if ileus) }\end{array}$ \\
\hline
\end{tabular}

Adapted from Cohen et al. [15].

${ }^{1}$ Neither oral nor parenteral metronidazole reach therapeutic concentrations in normal, nondiarrheal stool.

${ }^{2}$ Vancomycin needs to be delivered enterally to have effect

${ }^{3}$ To perform vancomycin retention enemas, insert an 18-inch foley catheter with $30 \mathrm{~mL}$ balloon into rectum, inflate balloon, instill vancomycin, clamp catheter for $60 \mathrm{~min}$, then deflate balloon and remove catheter with balloon.

$\mathrm{CDI}=$ Clostridium difficile infection; $\mathrm{PO}=$ oral $; \mathrm{IV}=$ intravenous; $\mathrm{TID}=3$ times daily; $\mathrm{WBC}=$ white blood cells; $\mathrm{QID}=4$ times daily; FDA $=$ U.S. Food and Drug Administration; q8h=every $8 \mathrm{~h}$; $\mathrm{NS}=$ normal saline; $\mathrm{q} 6 \mathrm{~h}=$ every $6 \mathrm{~h}$; ICU $=$ intensive care unit.

enterococci. It is active against clinical isolates of $C$. difficile, including the NAP1/BI/027 strains. As with oral vancomycin, there is minimal systemic absorption when the drug is given orally, with resultant high fecal concentrations. In vitro and in vivo studies also show limited activity against other components of the normal gut flora. The first published report of fidaxomicin efficacy was a randomized $(\mathrm{n}=629)$ trial comparing fidaxomicin (200 mg twice daily) or vancomycin (125 mg four times daily) orally for $10 \mathrm{~d}$.

Table 3B. Guidelines for Treatment of Recurrent CLOSTRIDIUM DIFFICILE INFECTION (CDI)

\begin{tabular}{lc}
\hline Recurrent disease & Up to 65\% recurrence rates \\
\hline $\begin{array}{l}\text { First } \\
\text { recurrence }\end{array}$ & Same treatment algorithm \\
& as for initial episode CDI \\
& -Recommend vancomycin if \\
& WBC $>15 \mathrm{k}$ or increasing serum \\
& creatinine concentration (higher risk) \\
$\begin{array}{l}\text { Second } \\
\text { recurrence }\end{array}$ & Vancomycin in a tapered \\
& or pulsed regimen \\
& -No metronidazole (neurotoxicity) \\
\hline
\end{tabular}

Adapted from Cohen et al. [15].

$\mathrm{WBC}=$ white blood cells .
The rates of clinical cure were non-inferior, but fidaxomicin was associated with a significantly lower rate of recurrence of CDI in patients with the NAP1 strain (15\% vs. $25 \%$ in modified intention-to-treat population; $p=0.005)$ [38,39]. In a multicenter, multinational, double-blind randomized controlled trial $(n=535)$ of fidaxomicin versus oral vancomycin, fidaxomicin was shown to have similar rates of clinical cure as oral vancomycin, with improved sustained response and decreased recurrence rates [40]. Fidaxomicin has recently received FDA approval for the treatment of CDI with a recommended treatment dose of $100 \mathrm{mg}$ by mouth (PO) twice daily (BID).

\section{Rifampin}

Rifampin displays potent activity against $C$. difficile strains but resistance remains a concern. In a study of $C$. difficile strains from hospitalized patients, 12 of 163 isolates were resistant to rifampin [41] and in a single-center Pittsburgh study, 36.8\% (173-470) strains displayed reduced susceptibility to rifampin [42]. In a clinical study of metronidazole monotherapy versus metronidazole/rifampin combination therapy, no difference in median time to resolution of symptoms or median time to first occurrence of relapse was identified in an interim analysis, and the study was ended early because there was little chance of demonstrating superiority with combination therapy including rifampin [43].

\section{Rifaximin}

Rifaximin is a nonabsorbable rifamycin derivative that inhibits bacterial RNA synthesis. Theoretical advantages include poor gastrointestinal tract absorption, intestinal lumen activity, and a low incidence for resistance. Rifaximin achieves high colonic concentrations and may spare usual enteric flora. It has a broad spectrum of activity against grampositive bacilli, gram-negative bacilli, aerobes, and anaerobes. Hence, it is an ideal drug used for traveler's diarrhea. The minimal inhibitory concentration (MIC) profile is superior to that of metronidazole and vancomycin.

A small randomized study confirmed equivalence of rifaximin with oral vancomycin [44]. Three case series have documented potential benefit with rifaximin to prevent CDI recurrence [45-47]. In one case series of patients with recurrent CDI, a dose of rifaximin $400 \mathrm{mg}$ PO BID for two weeks given immediately after the last course of oral vancomycin resulted in cure for seven out of eight patients [48]. However, some concerns were raised regarding antimicrobial resistance in one patient. An open label trial of rifaximin (400 mg PO three times daily [TID] for $10 \mathrm{~d}$ ) as first-line therapy in 13 hospitalized patients with CDI documented that all eight patients who completed the study had completed symptom resolution; one patient had recurrent infection during a repeat hospitalization [49]. In a report of 32 patients treated with rifaximin for recurrent $C$. difficile infection with $1 \mathrm{y}$ follow up, $53 \%$ of patients had no relapse. The MIC value of rifampin seemed to predict the response to rifaximin treatment [50].

A multicenter double-blind randomized controlled trial of rifaximin compared to vancomycin for $C$. difficile (NCT00269399) was completed; final results are pending. Rifaximin is currently approved by the FDA for travelers' diarrhea (200 mg PO TID for $3 \mathrm{~d}$ ) caused by non-invasive 


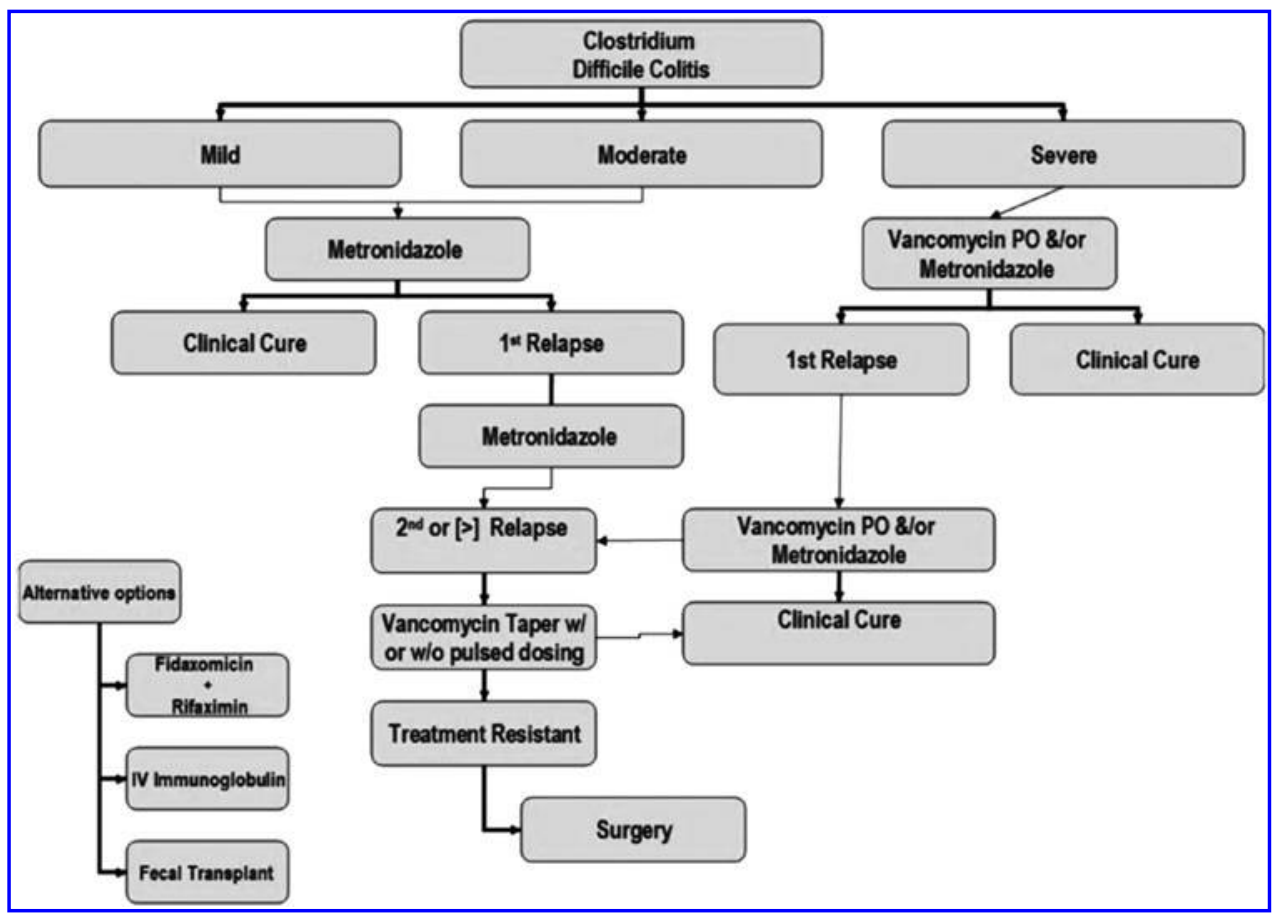

FIG. 4. Treatment algorithm for management of Clostridium difficile infection. From Joseph et al. [31].

strains of Escherichia coli and for reduction in the risk of overt hepatic encephalopathy recurrence (550 mg PO BID) in patients $18 \mathrm{y}$ or older but is not approved for the treatment of CDI.

\section{Nitazoxanide}

Nitazoxanide is synthetic nitrothiazolyl-salicylamide derivative used to treat protozoan and helminthic infections. This is also the only drug that is effective for cryptosporidiosis in patients who have acquired immune deficiency syn- drome. Nitazoxanide blocks anaerobic metabolism of eukaryocytes and inhibits $C$. difficile in vitro at low concentrations. Approximately two-thirds of the oral dose is excreted in the stool as the active metabolite tizoxanide. In a prospective, double-blind control trial, a 10-d course of nitazoxanide $500 \mathrm{mg}$ PO BID was as effective as metronidazole in the treatment of CDI [51]. In a second prospective doubleblind study of nitazoxanide versus oral vancomycin, the clinical response rate was no different $(77 \%$ nitazoxanide vs. $74 \%$ vancomycin) [52]. An open-label study in 35 CDI patients reported an overall response rate of $66 \%$. In these

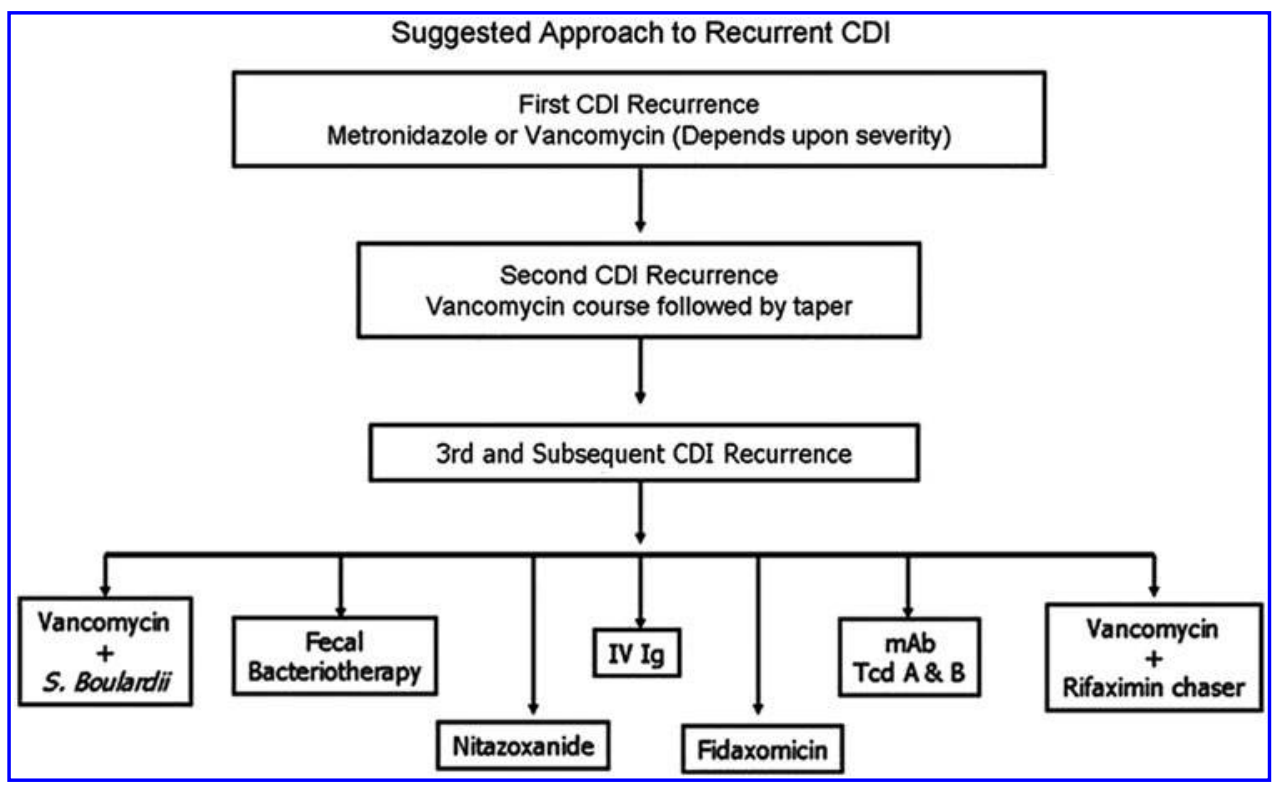

FIG. 5. Suggested approach to treatment of recurrent Clostridium difficile infection (CDI). From Cocanour [35]. IV $\mathrm{Ig}=$ intravenous immunoglobulin; $\mathrm{MAB}=$ monoclonal antibody. 
studies, the drug was well tolerated, with no serious adverse events reported.

\section{Tigecycline}

Tigecycline, a novel derivative of minocycline, has been used off-label in critically ill patients with severe complicated CDI whose infections did not respond to standard therapies. A report of seven cases confirmed that six of the seven patients were treated successfully with tigecycline therapy with treatment duration of two to four weeks. None of these patients experienced recurrence to date [53]. In vitro studies demonstrated a $90 \%$ MIC range for tigecycline of $0.016-0.25 \mathrm{mg} / \mathrm{L}$ for all $C$. difficile isolates. Tigecycline also exhibited good fecal penetration because of primary biliary excretion of unchanged drug, and as much as $59 \%$ of the dose is recovered in feces following administration over $4 \mathrm{~d}$ in health volunteers.

\section{Monoclonal antibodies}

One of the major incongruities in the management of CDI is that antibiotics are the mainstay of treatment for this antibiotic-associated condition. Non-antibiotic treatments such as monoclonal antibodies would be a welcome addition or replacement of current standard therapies.

The first Phase II human multicenter randomized doubleblind, placebo-controlled trial of two novel, neutralizing, fully human monoclonal antibodies against $C$. difficile toxins $\mathrm{A}$ and $\mathrm{B}$ had impressive results [54]. Recurrent infection developed in $7 \%$ (seven of 101) of the antibody group compared with $25 \%$ (25 of 99) in the placebo group, reflecting a relative reduction of $72 \%$. Interestingly, there was no effect on the duration or severity of the initial episode of infection. The antibodies were not immunogenic and adverse events were not different than placebo. The trial results are consistent with previous studies showing that inadequate circulating antibody levels against $C$. difficile toxins predispose patients to symptomatic and recurrent infection, and with observational data suggesting a benefit associated with passive and active immunization for secondary prevention. Although monoclonal antibodies will not be used for primary treatment, they will likely play a role in patients at risk for recurrent infection, and they may allow a reduction in the duration of standard antimicrobial therapy for acute CDI [55]. Additional Phase III human studies are underway examining the efficacy of monoclonal antibodies against toxins $\mathrm{A}$ and $\mathrm{B}$ in $C$. difficile disease (Table 4).

\section{Immunoglobulins}

Immunoglobulins have been studied retrospectively with some success in patients with severe and recurrent CDI. Since an inability to mount a protective immune response to C. difficile and its toxins appears to be responsible for susceptibility to recurrent infection [56,57], this treatment strategy has some merit. More than one-half of all adults have circulating antibodies against $C$. difficile toxins and normal pooled immunoglobulins can neutralize toxins A and B [58]. Intravenous pooled human immunoglobulin products have been used off-label and on an ad hoc basis for passive immunotherapy. However, pharmacokinetic and efficacy data for these products are not available. Variable results have been reported with this treatment strategy [59-63]. No randomized trial data are available.

\section{Fecal transplantation}

The use of fecal transplant from healthy donors is another treatment modality under investigation. Stool slurries are given via nasogastric tube or as enemas to CDI patients. A recent study randomized patients $(n=43)$ with recurrent $C D I$ to receive one of three therapies: An initial vancomycin regimen $(500 \mathrm{mg}$ orally four times per day for $4 \mathrm{~d})$, followed by bowel lavage and subsequent infusion of a solution of donor feces through a nasoduodenal tube; a standard vancomycin regimen (500 mg orally four times per day for $14 \mathrm{~d}$ ); or a standard vancomycin regimen with bowel lavage. The primary end point was the resolution of diarrhea associated with CDI without relapse after $10 \mathrm{wk}$. The study was stopped early after an interim analysis documented that $81 \%$ of the fecal transplantation cohort had resolution after the first infusion, compared with $31 \%$ (oral vancomycin therapy alone) and $23 \%$ (oral vancomycin with bowel lavage) in the other experimental cohorts $[64,65]$. This study, although small and unblinded, does confirm the efficacy of fecal transplantation for recurrent CDI.

\section{Active immunization}

The $C$. difficile toxoid vaccine was well tolerated and immunogenic in normal healthy subjects [66]. A report of vaccine use in three patients with recurrent infection documented that none had a subsequent relapse [67].

Currently, two vaccine candidates against CDI are being tested clinically. The more advanced program is that of Sanofi-Pasteur (Lyon, France) with the toxoid ACAMCDIFF $^{\mathrm{TM}}$ (NCT00772343 and NCT01230957). The vaccine candidate is composed of a mixture of formalin-inactivated toxin A and B that is given three times intramuscularly. The vaccine has been shown to be safe, well tolerated, and immunogenic in healthy adults $[68,69]$. Two phase II studies are currently being conducted in prophylactic and therapeutic settings to better define the optimal dose and to tackle the necessity of adsorbing the toxoids on aluminum salt [70]. Because the vaccine addresses an important unmet medical need, ACAM-CDIFF has been fast-tracked by the FDA.

In parallel, Intercell (Vienna, Austria) is now testing the safety, tolerability and immunogenicity of an anti-CDI vaccine candidate in an open-label, dose-escalating Phase I study in healthy volunteers (NCT01296386). In this study, one cohort includes individuals older than $65 \mathrm{y}$. The subunit vaccine developed by Intercell/Valneva consists of a recombinant fusion protein containing a part of the receptor-binding domain of toxins $\mathrm{A}$ and $\mathrm{B}$ administered with aluminum salt and given three times intramuscularly [71,72]. Although immunization appears promising, additional trials are warranted [73].

\section{Tolevamer, non-antibiotic polymer}

Tolevamer is a toxin-binding polymer that binds to the C. difficile toxin in the intestinal tract at doses of 3 to $6 \mathrm{~g}$ daily. It has no antibiotic properties, does not alter normal gut 
Table 4. Studies of Human Monoclonal Antibodies Against Clostridium difficile Toxins A and B

\begin{tabular}{|c|c|c|c|c|c|}
\hline $\begin{array}{l}\text { Candidates } \\
\text { and sponsor }\end{array}$ & $\begin{array}{c}\text { Therapeutic } \\
\text { agent }\end{array}$ & Formulation & $\begin{array}{l}\text { Development } \\
\text { stage }\end{array}$ & $\begin{array}{l}\text { Patient study } \\
\text { cohorts }\end{array}$ & Reference \\
\hline $\begin{array}{l}\text { Antitoxin A and } \\
\text { antitoxin } \\
\text { B monoclonal } \\
\text { antibodies } \\
\text { (Medarex and } \\
\text { Bristol-Myers } \\
\text { Squibb-Merck) }\end{array}$ & $\begin{array}{l}\text { Antitoxin } \\
\text { A and B } \\
\text { fully human } \\
\text { monoclonal } \\
\text { antibodies } \\
\text { targeting the } \\
\text { receptor- } \\
\text { binding } \\
\text { domain of } \\
\text { the toxins }\end{array}$ & $\begin{array}{l}\text { CDA1 } \\
\text { (antitoxin A) } \\
\text { plus CDB1 } \\
\text { (antitoxin B) } \\
\text { once at } 10 \mathrm{mg} / \mathrm{kg} \\
\text { in parallel } \\
\text { to standard } \\
\text { antibiotics }\end{array}$ & $\begin{array}{l}\text { Phase II } \\
\quad \text { (completed) }\end{array}$ & $\begin{array}{l}200 \text { patients } \\
\text { with } \\
\text { symptomatic } \\
\text { CDI }\end{array}$ & $\begin{array}{l}\text { Lowy et al. N Engl J } \\
\text { Med 2010;362:197-205. } \\
\text { Phase II clinical study } \\
\text { giving the proof-of- } \\
\text { concept of the efficacy } \\
\text { of a combination of two } \\
\text { monoclonal antibodies } \\
\text { plus antibiotic treatment } \\
\text { in the prevention } \\
\text { of relapse. }\end{array}$ \\
\hline $\begin{array}{l}\text { Biologic } \\
\text { MK-3415 } \\
\text { MK1-3415A, } \\
\text { MK-6072 } \\
\text { Merck }\end{array}$ & & $\begin{array}{l}\text { MK-3415 } \\
\text { (antitoxin A) } \\
\text { MK-6072 } \\
\text { (antitoxin B) } \\
\text { or } \\
\text { MK-3415A } \\
\text { (combination } \\
\text { of the two } \\
\text { antibodies) } \\
\text { at a single } \\
\text { administration of } \\
10 \text { mg/kg, with } \\
\text { antibiotic therapy }\end{array}$ & Phase III & $\begin{array}{l}\text { 1,600 patients } \\
\text { with } \\
\text { symptomatic } \\
\text { CDI and } \\
\text { under } \\
\text { antimicrobial } \\
\text { therapy } \\
\text { Primary } \\
\text { outcome measure } \\
\text { is CDI } \\
\text { recurrence }\end{array}$ & $\begin{array}{l}\text { A Phase III, Randomized, } \\
\text { Double-Blind, Placebo- } \\
\text { Controlled, Adaptive } \\
\text { Design Study of the } \\
\text { Efficacy, Safety, and } \\
\text { Tolerability of a Single } \\
\text { Infusion of MK-3415 } \\
\text { (Human Monoclonal } \\
\text { Antibody to Clostridium } \\
\text { Difficile Toxin A), MK- } \\
\text { 6072 (Human Monoclo- } \\
\text { nal Antibody to } \\
\text { Clostridium Difficile } \\
\text { Toxin B), and MK- } \\
\text { 3415A (Human } \\
\text { Monoclonal Antibodies } \\
\text { to C. difficile Toxin A } \\
\text { and Toxin B) in Patients } \\
\text { Receiving Antibiotic } \\
\text { Therapy for C. difficile } \\
\text { Infection (MODIFY I) } \\
\text { NCT01241552 } \\
\text { Study enrollment } \\
\text { ongoing: October 2011- } \\
\text { November 2014 }\end{array}$ \\
\hline $\begin{array}{l}\text { Biologic } \\
\text { MK-6072 } \\
\text { MK-3415A } \\
\text { Placebo } \\
\text { Merck }\end{array}$ & & $\begin{array}{l}\text { MK- } 6072 \\
\text { (antitoxin B) } \\
\text { or } \\
\text { MK-3415A } \\
\text { (combination } \\
\text { of the two } \\
\text { antibodies) at } \\
\text { a single } \\
\text { administration } \\
\text { of } 10 \mathrm{mg} / \mathrm{kg}, \\
\text { with antibiotic } \\
\text { therapy }\end{array}$ & Phase III & $\begin{array}{l}\text { 1,200 patients } \\
\text { with } \\
\text { symptomatic } \\
\text { CDI receiving } \\
\text { SOC therapy } \\
\text { Primary } \\
\text { outcome } \\
\text { measure } \\
\text { is CDI } \\
\text { recurrence }\end{array}$ & $\begin{array}{l}\text { A Phase III, Randomized, } \\
\text { Double-Blind, Placebo- } \\
\text { Controlled Study of the } \\
\text { Efficacy, Safety and } \\
\text { Tolerability of a Single } \\
\text { Infusion of MK-6072 } \\
\text { (Human Monoclonal } \\
\text { Antibody to C. Difficile } \\
\text { Toxin B), and MK- } \\
\text { 3415A (Human } \\
\text { Monoclonal Antibodies } \\
\text { to C. difficile Toxin A } \\
\text { and B) in Patients } \\
\text { Receiving Antibiotic } \\
\text { Therapy for C. difficile } \\
\text { Infection (MODIFY II) } \\
\text { NCT01513239 } \\
\text { Study enrollment } \\
\text { ongoing: February } 2012 \\
\text { - December } 2014\end{array}$ \\
\hline
\end{tabular}




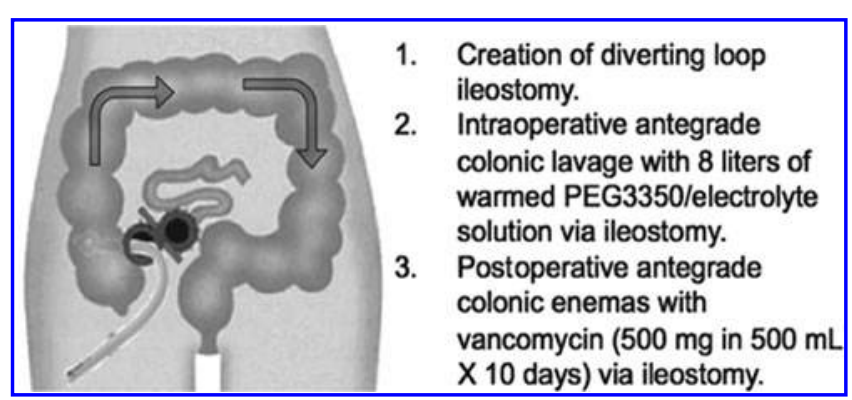

FIG. 6. Operative treatment for loop ileostomy and colonic lavage for severe, complicated $C$. difficile associated disease. When possible, laparoscopic exploration of the colon and abdominal cavity is performed and a loop ileostomy is created. The colon is then lavaged in an antegrade fashion through the ileostomy with a high volume (8 L) of polyethylene glycol 3350 or balanced electrolyte solution and the effluent is collected via a rectal drainage tube. A catheter is placed in the efferent limb of the ileostomy to deliver vancomycin flushes in an antegrade fashion in the postoperative period.

flora, and would not result in the development of resistant strains. It does not bind metronidazole or vancomycin. Early phase II trials reported similar outcomes to standard therapy in mild-to-moderate CDI, but Phase III clinical trials published in 2009 reported that it did not reduce the duration or magnitude of $C$. difficile toxin activity and further development has been terminated [74-76].

\section{Surgical Management}

\section{Timing of surgical consultation}

Surgical consultation should occur early in the course of disease in patients with severe and complicated $C$. difficile colitis, as surgical decision making is challenging and the clinical course of the disease is difficult to predict in any individual patient. Early surgical consultation is re-
Table 5. Proposed Indications for Ileostomy with Antegrade Colonic Lavage

Suspected or established diagnosis of CDI plus one or more of the following:

- Need for intensive care unit admission

- Hypotension necessitating vasopressor support

- Neurologic changes

- Respiratory failure necessitating mechanical ventilation

- Increasing white blood cell count $>20,000 / \mathrm{mm}^{3}$

- Lactate concentration $>5 \mathrm{mmol} / \mathrm{L}$

- Other signs of end-organ damage or new organ failure

commended for the critically ill patient with CDI [77]. A recent single-center study documented that survival rates were higher in patients cared for by surgical versus nonsurgical departments, possibly because of earlier and more frequent surgical intervention [78].

Furthermore, surgical consultation does not always recommend surgical intervention. A single-center case series report of 47 patients with severe $C$. difficile colitis with surgical consultation recommended initiation of an adjuvant intracolonic vancomycin enema $(1 \mathrm{~g} / 500 \mathrm{~mL}$ normal saline every $6 \mathrm{~h}$ ) protocol and $70 \%$ of patients responded with complete resolution without need for surgery. Multivariable logistic regression confirmed that acidosis and hypoalbuminemia were significantly associated with incomplete response to intracolonic vancomycin enema treatment [79].

\section{Total abdominal colectomy}

The indications for surgical management of patients with CDI are not defined clearly. Most clinicians advocate surgical intervention in patients with severe disease, worsening clinical condition and in those with peritonitis or shock states.

Total abdominal colectomy was the standard surgical procedure performed in these cases, but mortality rates were

Table 6. Recommendations for Infection Control and Prevention of Clostridium Difficile InfeCtion (CDI)

- A hospital-based infection control program can help to decrease the incidence of CDI. (Conditional recommendation, moderate-quality evidence)

- Routine screening for $C$. difficile in hospitalized patients without diarrhea is not recommended and asymptomatic carriers should not be treated. (Strong recommendation, low-quality evidence)

- Antibiotic stewardship is recommended to reduce the risk of CDI. (Strong recommendation, high-quality evidence)

- Contact precautions for a patient with CDI should be maintained at a minimum until the resolution of diarrhea. (Strong recommendation, high-quality evidence)

- Patients with known or suspected CDI should be placed in a private room or in a room with another patient with documented CDI. (Strong recommendation, high-quality evidence)

- Hand hygiene and barrier precautions, including gloves and gowns, should be used by all health-care workers and visitors entering the room of any patient with known or suspected CDI. (Strong recommendation, moderate-quality evidence)

- Single-use disposable equipment should be used for prevention of CDI transmission. Non-disposable medical equipment should be dedicated to the patient's room and other equipment should be thoroughly cleaned after use in a patient with CDI. (Strong recommendation, moderate-quality evidence)

- Disinfection of environmental surfaces is recommended using an Environmental Protection Agency (EPA)-registered disinfectant with $C$. difficile-sporicidal label claim or 5000 p.p.m. chlorine-containing cleaning agents in areas of potential contamination by $C$. difficile. (Strong recommendation, high-quality evidence)

- Although there is moderate evidence that two probiotics (Lactobacillus rhamnosus GG and Saccharomyces boulardii) decrease the incidence of antibiotic associated diarrhea, there is insufficient evidence that probiotics prevent $C$. difficile infection. (Strong recommendation, low-quality evidence)

From Surawicz et al. [25]. (Reprinted by permission from Macmillan Publishers Ltd.) 
high $[80,81]$ and most survivors required permanent ileostomy with long-term complications related to fluid losses from the ileostomy. Common indications for colectomy include colonic perforation, toxic megacolon with impending perforation, peritonitis, severe sepsis or septic shock, need for vasopressor support, new end-organ dysfunction or failure, and colitis refractory to medical management. All of these factors also are significant predictors of mortality.

A systematic review and meta-analysis of outcomes following emergency surgery for $C$. difficile colitis included 31 studies $(\mathrm{n}=1,433)$, and the most commonly performed surgery was total colectomy with end-ileostomy (89\%; 1,247 of 1,401 surgical procedures). When total colectomy was not performed, additional bowel resection was required in $15.9 \%$ of patients. The $30-\mathrm{d}$ mortality rate was $41.3 \%$. The strongest predictors of post-operative death were those relating to preoperative physiologic status: pre-operative intubation, acute renal failure, multiple organ failure, and shock requiring vasopressors [82].

\section{Diverting loop ileostomy and colonic irrigation}

More recently, an alternative surgical procedure to total abdominal colectomy has emerged with creation of a loop ileostomy, intraoperative colonic lavage via the ileostomy, and post-operative antegrade vancomycin flushes via the ileostomy (Fig. 6). The initial report of this procedure in 42 patients documented that the procedure was accomplished laparoscopically in $35(83 \%)$ patients. The new treatment strategy resulted in reduced mortality, compared with the authors' historical population who had undergone total abdominal colectomy $(19 \%$ vs. $50 \%$, OR $0.24 ; \mathrm{p}=0.006)$. Preservation of the colon was achieved in $39(93 \%)$ patients [83].

This new procedure is a potential surgical advance in the treatment of severe life-threatening CDI. Proposed indications for this surgical procedure are listed in Table 5. A single-institution prospective randomized trial is ongoing at the Massachusetts General Hospital (NCT01441271) comparing ileal diversion and colonic lavage with total abdominal colectomy for the treatment of fulminant $C$. difficile colitis.

\section{Infection Control}

Transmission of $C$. difficile is usually person-to-person, and via a fecal-oral route. The hands of healthcare workers and environmental fomites (such as bedpans, commodes, and rectal probes) are key players for spread of the bacterium and spores in acute care facilities. Thus, the best mode of preventing transmission is with the use of full contact isolation precautions (e.g., gloves, barrier gowns, private rooms, and disposable or dedicated supplies and equipment), as well as good hand hygiene and environmental cleaning. Contact precautions should be maintained at least until diarrhea is resolved. It is important to note that alcohol-based solutions do not kill $C$. difficile spores, and thus hand washing with soap and water is required to prevent spread via healthcare workers' hands [84]. Likewise, a bleach-based solution (5,000 ppm chlorine) or Environmental Protection Agency- registered disinfectant with a $C$. difficile sporicidal claim is required to kill spores in the environment. General guidelines for infection control and prevention are summarized in Table 6 .

\section{Summary}

C. difficile infection incidence and severity has grown dramatically in the past two decades, gaining increased significance as a clinically important disease entity. Treatment modalities vary based on CDI classification with regards to severity and timing of onset. The mainstay of medical treatment remains metronidazole (preferred due to substantial cost differential) and oral/rectal vancomycin. Other treatment modalities may be used in special circumstances, and more trials are underway to evaluate adjunctive treatment options such as monoclonal antibodies, vaccination, and fecal transplant. Early surgical consultation in severe cases of CDI and in patients with deteriorating clinical condition may be life-saving. Diverting loop ileostomy for antegrade colonic irrigation may allow for colonic preservation in the appropriate patient population. Infection control measures both at the individual as well as institution levels are vital to mitigating the spread of CDI.

\section{Author Disclosure Statement}

No competing financial interests exist.

\section{References}

1. Hall IC, O'Toole E. Intestinal flora in new-born infants: With a description of a new pathogenic anaerobe, Bacillus difficilis. Am J Dis Child 1935;49:390-402.

2. Bartlett JG. Clostridium difficile: History of its role as an enteric pathogen and the current state of knowledge about the organism. Clin Infect Dis 1994;18 Suppl 4:S265-S272.

3. Poutanen SM, Simor AE. Clostridium difficile-associated diarrhea in adults. CMHJ 2014;171:51-58.

4. Kyne L, Farrell RJ, Kelly CP. Clostridium difficile. Gastroenterol Clin North Am. 2001;30:753-777.

5. McDonald LC, Coignard B, Dubberke E, et al. Recommendations for surveillance of Clostridium difficileassociated disease. Infect Control Hosp Epidemiol 2007;28: 140-145.

6. McDonald LC, Owings M, Jernigan JB. Clostridium difficile infection in patients discharged from US short-stay hospitals, 1996 to 2003. Emerg Infect Dis 2006;12:409-415.

7. Harbrecht BG, Franklin GA, Shirley RM, et al. Statewide experience with Clostridium difficile colitis in academic and non-academic medical centers. Surg Infect (Larchmt) 2012;13:88-92.

8. Khanna S, Pardi DS. The growing incidence and severity of Clostridium difficile infection in inpatient and outpatient settings. Expert Rev Gastroenterol Hepatol 2010;4:409_ 416.

9. Kelly CP, LaMont JT. Clostridium difficile-More difficult than ever. N Engl J Med 2008;359:1932-1940.

10. United Kingdom national statistics. Newport, United Kingdom: Office for National Statistics, UK Statistics Authority. www.statistics.gov.uk (Last accessed July 27, 2013).

11. Pepin J, Valiquette L, Alary ME, et al. Clostridium difficileassociated diarrhea in a region of Quebec from 1991 to 2003: A changing pattern of disease severity. CMAJ 2004; 171:466-472.

12. Loo VG, Poirier L, Miller MA, et al. A predominantly clonal multi-institutional outbreak of Clostridium difficileassociated diarrhea with high morbidity and mortality. $\underline{\mathrm{N}}$ Engl J Med 2005;353:2442-2449. 
13. Micek ST, Schramm G, Morrow L, et al. Clostridium difficile infection: A multicenter study of epidemiology and outcomes in mechanically ventilated patients. $\underline{\text { Crit Care }}$ Med 2013;41:1968-1975.

14. Kelly CP. C. difficile infection: Tools for treatment and prevention. www.medscape.org/viewarticle/584850

15. Cohen SH, Gerding DN, Johnson S, et al; Society for Healthcare Epidemiology of America; Infectious Diseases Society of America. Clinical practice guidelines for Clostridium difficile infection in adults: 2010 update by the society for healthcare epidemiology of America (SHEA) and the infectious diseases society of America (IDSA). Infect Control Hosp Epidemiol 2010;31:431-455.

16. Warny M, Pepin J, Fang A, et al. Toxin production by an emerging strain of Clostridium difficile associated with outbreaks of severe disease in North America and Europe. Lancet 2005;366:1079-1084.

17. Bartlett JG. Narrative review: The new epidemic of Clostridium difficile-associated enteric disease. Ann Intern Med 2006;145:758-64.

18. He M, Miyajima F, Roberts P, Ellison L, et al. Emergence and global spread of epidemic healthcare-associated Clostridium difficile. Nat Genet 2013;45:109-113.

19. Zerey M, Paton BL, Lincourt AE, et al. The burden of Clostridium difficile in surgical patients in the United States. Surg Infect (Larchmt) 2007;8:557-566.

20. Johnson S, Gerding DN. Clostridium difficile-associated diarrhea. Clin Infect Dis 1998;26:1027-1034.

21. McFarland LV, Mulligan ME, Kwok RY, Stamm WE. Nosocomial acquisition of Clostridium difficile infection. $\underline{\mathrm{N}}$ Engl J Med 1989;320:204-210.

22. Dial S, Delaney JA, Barkun AN, Suissa S. Use of gastric acid-suppressive agents and the risk of communityacquired Clostridium difficile-associated disease. JAMA 2005;294:2989-2995.

23. Carroll KC. Tests for the diagnosis of Clostridium difficile infection: The next generation. Anaerobe 2011;17:170174.

24. Quinn CD, Sefers SE, Babiker W, et al. C. Diff Quik Chek complete enzyme immunoassay provides a reliable firstline method for detection of Clostridium difficile in stool specimens. J Clin Microbiol 2010;48:603-605.

25. Surawicz CM, Brandt LJ, Binion DG, et al. Guidelines for diagnosis, treatment and prevention of Clostridium difficile infections. Am J Gastroenterology 2013;108:478498.

26. http://www.gastrointestinalatlas.com/English/Colon-andRectum/_Pseudomembranous_Colitis/_pseudomembranous_ colitis/html

27. http://emedicine.medscape.com/), 2014, available at: http:// emedicine.medscape.com/article/366987-overview

28. Ash L, Baker ME, O’Malley CM Jr, et al. Colonic abnormalities on CT in adult hospitalized patients with Clostridium difficile colitis: Prevalence and significance of findings. AJR Am J Roentgenol 2006;186:1393-1400.

29. Macari M, Balthazar EJ, Megibow AJ. The accordion sign at CT: A nonspecific finding in patients with colonic edema. Radiology 1999;211:743-746.

30. Kirkpatrick ID, Greenberg HM. Evaluating the CT diagnosis of Clostridium difficile colitis: should CT guide therapy? AJR Am J Roentgenol 2001;176:635-639.

31. Joseph J, Singhal S, Patel GM, Anand S. Clostridium difficile colitis: Review of the therapeutic approach. Am J Ther 2014;21:385-394.
32. Zar FA, Bakkanagari SR, Moorthi KM, Davis MB. A comparison of vancomycin and metronidazole for the treatment of Clostridium difficile-associated diarrhea, stratified by disease severity. Clin Infect Dis 2007;45:302-307.

33. Aslam S, Hamill RJ, Musher DM. Treatment of Clostridium difficile-associated disease: Old therapies and new strategies Lancet Infect Dis 2005;5:549-557.

34. Wilcox MH, Howe R. Diarrhoea caused by Clostridium difficile: Response time for treatment with metronidazole and vancomycin. J Antimicrob Chemother 1995;36:673679.

35. Cocanour CS. Best strategies in recurrent or persistent Clostridium difficile infection. Surg Infect 2011;12:235239.

36. Shah D, Dang MD, Hasbun R, et al. Clostridium difficile infection: update on emerging antibiotic treatment options and antibiotic resistance. Expert Rev Anti Infect Ther 2010;8:555-564.

37. Venuto C, Butler M, Ashley ED, Brown J. Alternative therapies for Clostridium difficile infections. Review of therapeutics. Pharmacotherapy 2010;30:1266-1278.

38. Louie TJ, Miller MA, Mullane KM, et al; OPT-80-003 Clinical Study Group. Fidaxomicin versus vancomycin for Clostridium difficile infection. N Engl J Med 2011;364: 422-431.

39. DuPont HL. The search for effective treatment of Clostridium difficile infection. N Engl J Med 2011;364:473475.

40. Cornely OA, Crook DW, Esposito R, et al. Fidaxomicin versus vancomycin for infection with Clostridium difficile in Europe, Canada, and the USA: A double-blind, noninferiority, randomised controlled trial. Lancet Infect Dis 2012;12:281-289.

41. Jiang ZD, DuPont HL, LaRocco M, Garey KW. In vitro susceptibility of Clostridium difficile to rifaximin and rifampin in 359 consecutive isolates at a university hospital in Houston, Texas. J Clin Pathol 2010;63:355-358.

42. Curry SR, Marsh JW, Shutt KA et al. High frequency of rifampin resistance identified in an epidemic Clostridium difficile clone from a large teaching hospital. $\underline{\text { Clin Infect }}$ Dis 2009;48:425-429.

43. Lagrotteria D, Holmes S, Smieja M, et al. Prospective, randomized inpatient study of oral metronidazole versus oral metronidazole and rifampin for treatment of primary episode of Clostridium difficile-associated diarrhea. $\underline{\text { Clin }}$ Infect Dis 2006;43:547-552.

44. Boero M, Berti E, Morgando A, Verme G. Treatment for colitis caused by Clostridium difficile: results of a randomized, open-label study of rifaximin vs. vancomycin. Microbiologia Medica 1990;5:74-77.

45. Johnson S, Schriever C, Patel U et al. Rifaximin redux: treatment of recurrent Clostridium difficile infections with Rifaximin immediately post-vancomycin treatment. Anaerobe 2009;15:290-291.

46. Garey KW, Jiang ZD, Bellard A, Dupont HL. Rifaximin in treatment of recurrent Clostridium difficile-associated diarrhea: an uncontrolled pilot study. J Clin Gastroenterol 2009;43:91-93.

47. Neff G, Zacharias V, Kaiser TE, et al. Rifaximin for the treatment of recurrent Clostridium difficile infection after liver transplantation: A case series. Liver Transplantation 2010;16:960-963.

48. Johnson S, Schriever C, Galang M, et al. Interruption of recurrent Clostridium difficile-associated diarrhea episodes 
by serial therapy with vancomycin and rifaximin. Clin Infect Dis 2007;44:846-848.

49. Rubin DT, Sohi S, Glathar M, et al. Rifaximin is effective for the treatment of Clostridium difficile-associated diarrhea: Results of an open-label pilot study. Gastroenterol Res Pract 2011;2011:106978.

50. Mattila E, Arkkila P, Mattila PS, et al. Rifaximin in the treatment of recurrent Clostridium difficile infection. Aliment Pharmacol Ther 2013;37:122-128.

51. Musher DM, Logan N, Hamill RJ, et al. Nitazoxanide for the treatment of Clostridium difficile colitis. Clin Infect Dis 2006;43:421-427.

52. Musher DM, Logan N, Bressler AM, et al. Nitazoxanide versus vancomycin in Clostridium difficile infection: A randomized, double-blind study. Clin Infect Dis 2009;48:41-46.

53. Larson KC, Belliveau PP, Spooner LM. Tigecycline for the treatment of severe Clostridium difficile infection. Ann Pharmacother 2011;45:1005-1010.

54. Lowy I, Molrine DC, Leav BA, et al. Treatment with monoclonal antibodies against Clostridium difficile toxins. N Engl J Med 2010;362:197-205.

55. Kyne L. Clostridium difficile-Beyond antibiotics. N Engl J Med 2010;362:264-265.

56. Kyne L, Warny M, Qamar A, Kelly CP. Asymptomatic carriage of Clostridium difficile and serum levels of IgG antibody against toxin A. N Engl J Med 2000;342:390-397.

57. Kyne L, Warny M, Qamar A, Kelly CP. Association between antibody response to toxin A and protection against recurrent Clostridium difficile diarrhoea. Lancet 2001;357: 189-193.

58. Kelly CP, Pothoulakis C, Orellana J, LaMont JT. Human colonic aspirates containing immunoglobulin A antibody to Clostridium difficile toxin A inhibit toxin A-receptor binding. Gastroenterology 1992;102:35-40.

59. Aldeyab MA, McElnay JC, Scott MG, et al. An evaluation of the impact of a single-dose intravenous immunoglobulin regimen in the treatment of Clostridium difficile infections. Infect Control Hosp Epidemiol 2011;32:631-633.

60. Juang P, Skledar SJ, Zgheib NK, et al. Clinical outcomes of intravenous immune globulin in severe Clostridium difficile-associated diarrhea. Am J Infect Control 2007;35: 131-137.

61. Salcedo J, Keates S, Pothoulakis C, et al. Intravenous immunoglobulin therapy for severe Clostridium difficile colitis. Gut 1997;41:366-370.

62. Leung DY, Kelly CP, Boguniewicz M, et al. Treatment with intravenously administered gamma globulin of chronic relapsing colitis induced by Clostridium difficile toxin. $\underline{\mathbf{J}}$ Pediatr 1991;118:633-637.

63. Wilcox MH. Descriptive study of intravenous immunoglobulin for the treatment of recurrent Clostridium difficile diarrhoea. J Antimicrob Chemother 2004;53:882-884.

64. Van Nood E, Vrieze A, Nieuwdorp M, et al. Duodenal infusion of donor feces for recurrent Clostridium difficile. $\underline{\mathrm{N}}$ Engl J Med 2013;368:407-415.

65. Kelly CP. Fecal microbiota transplantation-An old therapy comes of age. N Engl J Med 2013;368:474-475.

66. Kotloff KL, Wasserman SS, Losonsky GA, et al. Safety and immunogenicity of increasing doses of a Clostridium difficile toxoid vaccine administered to healthy adults. Infect Immun 2001;69:988-995.

67. Sougioultzis S, Kyne L, Drudy D, et al. Clostridium difficile toxoid vaccine in recurrent $\mathrm{C}$. difficile-associated diarrhea. Gastroenterology 2005;128:764-770.
68. Aboudola S, Kotloff KL, Kyne L et al. Clostridium difficile vaccine and serum immunoglobulin $\mathrm{G}$ antibody response to toxin A. Infect. Immun 2003;71:1608-1610.

69. Kotloff KL, Wasserman SS, Losonsky GA et al. Safety and immunogenicity of increasing doses of a Clostridium difficile toxoid vaccine administered to healthy adults. Infect Immun 2001;69:988-995.

70. Study of a Clostridium difficile toxoid vaccine (ACAMCDIFF $^{\mathrm{TM}}$ ) in subjects with Clostridium difficile infection. http://clinicaltrials.gov/ct2/show/NCT00772343

71. Valneva. Clostridium difficile. www.valneva.com/?page $=$ 85 (Last accessed April 14, 2014).

72. Rebeaud F, Bachmann MF. Immunization strategies for Clostridium difficile infections. Expert Rev Vaccines 2012; 11:469-479.

73. Lee BY, Popovich MJ, Tian Y, et al. The potential value of Clostridium difficile vaccine: an economic computer simulation model. Vaccine 2010;28:5245-5253.

74. Weiss K. Toxin-binding treatment for Clostridium difficile: a review including reports of studies with tolevamer. Int J Antimicrob Agents 2009;33:4-7.

75. Baines SD, Freeman J, Wilcox MH. Tolevamer is not efficacious in the neutralization of cytotoxin in a human gut model of Clostridium difficile infection. Antimicrob Agents Chemother 2009;53:2202-2204.

76. Nelson RL, Kelsey P, Leeman H, et al. Antibiotic treatment for Clostridium difficile-associated diarrhea in adults. Cochrane Database Syst Rev 2011;(9):CD004610.

77. Musher DM, Aslam S. Treatment of Clostridium difficile colitis in the critical care setting. Crit Care Clin 2008;24:279-91.

78. Sailhamer EA, Carson K, Chang Y, et al. Fulminant Clostridium difficile colitis: Patterns of care and predictors of mortality. Arch Surg 2009;144:433-439.

79. Kim PK, Huh HC, Cohen HW, et al. Intracolonic vancomycin for severe Clostridium difficile colitis. Surg Infect 2013;14:532-539.

80. Longo WE, Mazuski JE, Virgo KS, et al. Outcome after colectomy for Clostridium difficile colitis. Dis Colon Rectum 2004;47:1620-1626.

81. Koss K, Clark MA, Sanders DS, et al. The outcome of surgery in fulminant Clostridium difficile colitis. $\underline{\text { Colorectal }}$ Dis 2006;8:149-54.

82. Bhangu A, Nepogodiev D, Gupta A, et al; West Midlands Research Collaborative. Systematic review and metaanalysis of outcomes following emergency surgery for Clostridium difficile colitis. Br J Surg 2012;99:1501-1513.

83. Neal MD, Alverdy JC, Hall DE, et al. Diverting loop ileostomy and colonic lavage. An alternative to total abdominal colectomy for the treatment of severe complicated Clostridium difficile-associated disease. Ann Surg 2011;254:423-429.

84. Oughton MT, et al. Hand hygiene with soap and water is superior to alcohol rub and antiseptic wipes for removal of Clostridium difficile. Infect Control Hosp Epidemiol 2009; 30:939-944.

Address correspondence to: Dr. Kathleen B. To Division of Acute Care Surgery Department of Surgery University of Michigan University Hospital 1 C340 1500 East Medical Center Dr. Ann Arbor, MI 48109-0033

E-mail:kato@umich.edu 


\section{This article has been cited by:}

1. Sara Maghdoori, Seyed M. Moghadas. 2017. Assessing the effect of patient screening and isolation on curtailing Clostridium difficile infection in hospital settings. BMC Infectious Diseases 17:1. . [Crossref]

2. Patrizia Spigaglia, Fabrizio Barbanti, Elio Castagnola, Maria Cristina Diana, Luisa Pescetto, Roberto Bandettini. 2017. Clostridium difficile causing pediatric infections: New findings from a hospital-based study in Italy. Anaerobe 48, 262-268. [Crossref]

3. Lena M. Napolitano, Charles E. Edmiston. 2017. Clostridium difficile disease: Diagnosis, pathogenesis, and treatment update. Surgery 162:2, 325-348. [Crossref]

4. Guihua Tang, Wen Yin, Wenen Liu. 2017. Is frozen fecal microbiota transplantation as effective as fresh fecal microbiota transplantation in patients with recurrent or refractory Clostridium difficile infection: A meta-analysis?. Diagnostic Microbiology and Infectious Disease 88:4, 322-329. [Crossref]

5. Harminder Singh, Zoann Nugent, B. Nancy Yu, Lisa M. Lix, Laura E. Targownik, Charles N. Bernstein. 2017. Higher Incidence of Clostridium difficile Infection Among Individuals With Inflammatory Bowel Disease. Gastroenterology 153:2, 430-438.e2. [Crossref]

6. Małgorzata Aptekorz, Anna Szczegielniak, Barbara Wiechuła, Celine Harmanus, Ed Kuijper, Gayane Martirosian. 2017. Occurrence of Clostridium difficile ribotype 027 in hospitals of Silesia, Poland. Anaerobe 45, 106-113. [Crossref]

7. Harminder Singh, Zoann Nugent, B. Nancy Yu, Lisa M. Lix, Laura Targownik, Charles Bernstein. 2017. Hospital discharge abstracts have limited accuracy in identifying occurrence of Clostridium difficile infections among hospitalized individuals with inflammatory bowel disease: A population-based study. PLOS ONE 12:2, e0171266. [Crossref]

8. M.J. Pucci, C. Callebaut, A. Cathcart, K. Bush. Recent Epidemiological Changes in Infectious Diseases 511-552. [Crossref]

9. Ana Paula Vieira Colombo, Clarissa Bichara Magalhães, Fátima Aparecida Rocha Resende Hartenbach, Renata Martins do Souto, Carina Maciel da Silva-Boghossian. 2016. Periodontal-disease-associated biofilm: A reservoir for pathogens of medical importance. Microbial Pathogenesis 94, 27-34. [Crossref]

10. 2016. Treat Clostridium difficile infection in the elderly based on disease severity and history of recurrence. Drugs \& Therapy Perspectives 32:4, 149-153. [Crossref]

11. Patrizia Spigaglia. 2016. Recent advances in the understanding of antibiotic resistance in Clostridium difficile infection. Therapeutic Advances in Infectious Disease 3:1, 23-42. [Crossref]

12. Massimo Sartelli, Mark A. Malangoni, Fikri M. Abu-Zidan, Ewen A. Griffiths, Stefano Di Bella, Lynne V. McFarland, Ian Eltringham, Vishal G. Shelat, George C. Velmahos, Ciarán P. Kelly, Sahil Khanna, Zaid M. Abdelsattar, Layan Alrahmani, Luca Ansaloni, Goran Augustin, Miklosh Bala, Frédéric Barbut, Offir Ben-Ishay, Aneel Bhangu, Walter L. Biffl, Stephen M. Brecher, Adrián Camacho-Ortiz, Miguel A. Caínzos, Laura A. Canterbury, Fausto Catena, Shirley Chan, Jill R. Cherry-Bukowiec, Jesse Clanton, Federico Coccolini, Maria Elena Cocuz, Raul Coimbra, Charles H. Cook, Yunfeng Cui, Jacek Czepiel, Koray Das, Zaza Demetrashvili, Isidoro Di Carlo, Salomone Di Saverio, Irina Magdalena Dumitru, Catherine Eckert, Christian Eckmann, Edward H. Eiland, Mushira Abdulaziz Enani, Mario Faro, Paula Ferrada, Joseph Derek Forrester, Gustavo P. Fraga, Jean Louis Frossard, Rita Galeiras, Wagih Ghnnam, Carlos Augusto Gomes, Venkata Gorrepati, Mohamed Hassan Ahmed, Torsten Herzog, Felicia Humphrey, Jae Il Kim, Arda Isik, Rao Ivatury, Yeong Yeh Lee, Paul Juang, Luis Furuya-Kanamori, Aleksandar Karamarkovic, Peter K Kim, Yoram Kluger, Wen Chien Ko, Francis D. LaBarbera, Jae Gil Lee, Ari Leppaniemi, Varut Lohsiriwat, Sanjay Marwah, John E. Mazuski, Gokhan Metan, Ernest E. Moore, Frederick Alan Moore, Carl Erik Nord, Carlos A. Ordoñez, Gerson Alves Pereira Júnior, Nicola Petrosillo, Francisco Portela, Basant K. Puri, Arnab Ray, Mansoor Raza, Miran Rems, Boris E. Sakakushev, Gabriele Sganga, Patrizia Spigaglia, David B. Stewart, Pierre Tattevin, Jean Francois Timsit, Kathleen B. To, Cristian Tranà, Waldemar Uhl, Libor Urbánek, Harry van Goor, Angela Vassallo, Jean Ralph Zahar, Emanuele Caproli, Pierluigi Viale. 2015. WSES guidelines for management of Clostridium difficile infection in surgical patients. World Journal of Emergency Surgery 10:1. . [Crossref]

13. Nicholas A. Bodmer, Kiran H. Thakrar. 2015. Evaluating the Patient with Left Lower Quadrant Abdominal Pain. Radiologic Clinics of North America 53:6, 1171-1188. [Crossref]

14. Masako Mizusawa, Shira Doron, Sherwood Gorbach. 2015. Clostridium difficile Diarrhea in the Elderly: Current Issues and Management Options. Drugs \& Aging 32:8, 639-647. [Crossref]

15. Stephen M Vindigni, Christina M Surawicz. 2015. C. difficile Infection: Changing Epidemiology and Management Paradigms. Clinical and Translational Gastroenterology 6:7, e99. [Crossref] 